\title{
Comparative Chloroplast Genome Analyses of Species in Gentiana section Cruciata (Gentianaceae) and the Development of Authentication Markers
}

\author{
Tao Zhou ${ }^{1}$, Jian Wang ${ }^{1}$, Yun Jia ${ }^{2}$, Wenli Li ${ }^{1}$, Fusheng $\mathrm{Xu}^{1}$ and Xumei Wang ${ }^{1, *}$ \\ 1 School of Pharmacy, Xi'an Jiaotong University, Xi'an 710061, China; zhoutao196@mail.xjtu.edu.cn (T.Z.); \\ wangjian6318@126.com (J.W.); lw13659003@stu.xjtu.edu.cn (W.L.); xfs19940903@stu.xjtu.edu.cn (F.X.) \\ 2 Key Laboratory of Resource Biology and Biotechnology in Western China (Ministry of Education), \\ School of Life Sciences, Northwest University, Xi'an 710069, China; jy878683@163.com \\ * Correspondence: wangxumei@mail.xjtu.edu.cn; Tel.: +86-29-8265-5424
}

Received: 16 May 2018; Accepted: 3 July 2018; Published: 5 July 2018

\begin{abstract}
Gentiana section Cruciata is widely distributed across Eurasia at high altitudes, and some species in this section are used as traditional Chinese medicine. Accurate identification of these species is important for their utilization and conservation. Due to similar morphological and chemical characteristics, correct discrimination of these species still remains problematic. Here, we sequenced three complete chloroplast (cp) genomes (G. dahurica, G. siphonantha and G. officinalis). We further compared them with the previously published plastomes from sect. Cruciata and developed highly polymorphic molecular markers for species authentication. The eight $\mathrm{cp}$ genomes shared the highly conserved structure and contained 112 unique genes arranged in the same order, including 78 protein-coding genes, 30 tRNAs, and 4 rRNAs. We analyzed the repeats and nucleotide substitutions in these plastomes and detected several highly variable regions. We found that four genes $(a c c D, c l p P$, matK and $y c f 1)$ were subject to positive selection, and sixteen InDel-variable loci with high discriminatory powers were selected as candidate barcodes. Our phylogenetic analyses based on plastomes further confirmed the monophyly of sect. Cruciata and primarily elucidated the phylogeny of Gentianales. This study indicated that cp genomes can provide more integrated information for better elucidating the phylogenetic pattern and improving discriminatory power during species authentication.
\end{abstract}

Keywords: Gentiana section Cruciata; chloroplast genome; molecular markers; species authentication

\section{Introduction}

Gentiana is the largest genus in the family Gentianaceae and widely distributed throughout the northern Hemisphere [1]. Approximately 362 species are recognized in genus Gentiana which have been divided into 15 sections [2]. Section Cruciata contains 21 species which are mainly distributed in eastern Eurasia [3]. Most species of this section are restricted to alpine regions, although some of them could be found at altitudes below $1000 \mathrm{~m}$ at higher latitudes [1]. Four species (G. macrophylla, G. crassicaulis, G. straminea, and G. dahurica) in sect. Cruciata are used as the original plants of traditional Chinese medicine named Qin-jiao [4]. The roots of these plants contain abundant secoiridoid active compounds which could be used for the treatment of diabetes, apoplexy, paralysis, and rheumatism [5-8].

Recently, the wild resources of some Gentiana species are dramatically declined due to overexploitation and some of them have been listed in the National Key Protected Wild Herbs in China $[5,7]$. However, the demand of natural sources for these plants remains high due to the high pharmacological and economical values. Therefore, many economically motivated adulterants of Qin-jiao products with similar morphological characters have been developed to substitute the 
genuine medicinal materials. Generally, the authentication of herbs was based on the morphological and histological inspection. But these methods may not be suitable for authenticating some species in sect. Cruciata due to the following reasons. Firstly, most species of sect. Cruciata shared the similar morphological characters especially in terms of leaf shape. Secondly, some species in this section are usually located in the sympatric distributions, thus intermediate morphology could be detected due to interspecific hybridization $[9,10]$. Thirdly, pharmacognostical studies showed that some species such as G. siphonantha and G. straminea usually shared similar chemical profiles [11]. Some other factors, such as growth conditions, developmental stage, and internal metabolism may affect the secondary metabolite accumulation in Qin-jiao and limit the application of such chemical analyses for authenticating the species of sect. Cruciata. In addition, chemical methods for identifying the medicinal plants are also expensive and not suitable for high-throughput analysis [12]. Therefore, reliable and cost-efficient methods are needed to authenticate the medical plants of sect. Cruciata.

Chloroplast (cp) genome of angiosperm is characterized by a typical quadripartite structure that contains a pair of inverted repeat (IR) regions separated by a large single-copy (LSC) and a small single-copy (SSC) region [13], and it is highly conserved compared to nuclear and mitochondrial genomes. Although chloroplast genomes are highly conserved, some hotspot regions with single nucleotide polymorphisms and insertion/deletions could be found and these regions may provide enough information for species identification $[14,15]$. Due to low recombination, uniparental inheritance, and low nucleotide substitution rates, many cp genetic markers have been used for plant phylogenetic, phylogeographic, and population genetic analyses [16]. It has been proven that some chloroplast sequences such as $t r n H-p s b A, r b c L$, and matK were commonly used as DNA barcodes for plants discrimination [17]. But in some cases, above commonly used DNA barcodes were not suitable to distinguish closely related plants due to limited variation loci $[16,18]$. Recently, it has been proposed that the complete cp genome could be used as a plant barcode, and various research have demonstrated that complete $\mathrm{cp}$ genome can greatly increase resolution for resolving difficult phylogenetic relationships at lower taxonomic levels [16,19-22]. In addition, using the cp genome as a genetic marker for identifying the plant will avoid the problems such as gene deletion and low Polymerase Chain Reaction (PCR) efficiency [23].

Most species in section Cruciata were recently diverged and originated from a common radiation in the Qinghai-Tibet Plateau (QTP) before the Pleistocene [1,10], therefore these species were usually closely related and showed parallel evolutionary relationships [1]. Previous research showed that commonly used DNA barcodes in some cases may not be suitable to identify the medicinal plant of this section $[24,25]$. Therefore, more specific barcodes with enough variation are needed to discriminate closely related species belong to sect. Cruciata. Nowadays, with the improvement of sequencing and assembly technologies, it is comparatively simple to obtain comprehensive chloroplast sequences for identifying Gentiana species. By utilizing the variable information provided from cp genomes, we can not only obtain more specific barcodes for species authentication in sect. Cruciata, but also shed light on the complex evolutionary relationships of the species in this section.

In the present study, we obtained the chloroplast genome sequences of G. dahurica, G. siphonantha and G. officinalis by using de novo assembly of whole-genome sequencing (WGS) data derived from high throughput sequencing technology. We also comparatively analyzed the chloroplast genomes of eight species in sect. Cruciata and developed credible cp genome derived InDel markers to authenticate these species. These markers are not only valuable tools for further evolutionary and population genetic studies on Gentiana, but also could be used as standardized barcodes for authenticating the original plants of Qin-jiao. 


\section{Results}

\subsection{Complete Chloroplast Genome Features of Sect. Cruciata}

The chloroplast genomes of G. dahurica, G. siphonantha, and G. officinalis were sequenced with approximately 5.2, 5.8, and $5.6 \mathrm{~Gb}$ of paired-end reads, respectively. The raw reads with a sequence length of $125 \mathrm{bp}$ were trimmed to generate the clean reads for the next assembly. After quality filtering, $10,114,902,11,405,694$, and 11,288,676 clean reads were recovered for G. dahurica, G. siphonantha and G. officinalis, respectively. Combined with the de novo and reference guided assembly, the cp genomes were obtained. The four junction regions between the IRs and SSC/LSC regions were confirmed by PCR amplification and Sanger sequencing. We mapped the obtained sequences to the new assembled genomes and no mismatch or InDel was observed. We compared the basic genome features of three newly sequenced cp genomes with five previously published cp genomes [26-28] and found that all the chloroplast genomes possessed the typical quadripartite structure with the length range from 148,765 to 149,916 bp (Table 1, Figure 1). The whole cp genome contained a pair of inverted repeat regions (IRs: 24,955-25,337 bp) which were separated by a small single copy region (SSC: 17,070-17,095 bp) and a large single copy region (LSC: 81,119-82,911 bp) (Table 1). Although genomic structure and size were highly conserved in eight cp genomes, the IR/SC boundary regions still varied slightly (Figure 2). All the eight chloroplast genomes contained 112 unique genes arranged in the same order, including 78 protein-coding genes, 30 tRNA genes, and 4 rRNA genes. Two genes ( $r p s 16$, infA) were inferred to be pseudogenes (Figure S1). The overall guanine and cytosine (GC) content in each chloroplast genome is identically $37.7 \%$ (Table 1 ).

Table 1. Summary of complete chloroplast genomes for eight Gentiana species.

\begin{tabular}{lcccc}
\hline Name of Taxon & G. dahurica & G. siphonantha & G. officinalis & G. straminea \\
\hline Genome length & 148,803 & 148,908 & 148,879 & 148,991 \\
LSC length & 81,154 & 81,121 & 81,119 & 81,240 \\
SSC length & 17,093 & 17,113 & 17,088 & 17,085 \\
IR length & 25,278 & 25,337 & 25,336 & 25,333 \\
Total gene number & 112 & 112 & 112 & 112 \\
No. of protein coding genes & 78 & 78 & 78 & 78 \\
No. of tRNA genes & 30 & 30 & 30 & 30 \\
No. of rRNA genes & 4 & 4 & 4 & 4 \\
GC content in genome (\%) & 37.7 & 37.7 & 37.7 & 37.7 \\
\hline Name of Taxon & G. crassicaulis & G. robusta & G. tibetica & G. macrophylla \\
\hline Genome length & 148,776 & 148,911 & 148,765 & 149,916 \\
LSC length & 81,164 & 81,164 & 81,163 & 82,911 \\
SSC length & 17,071 & 17,085 & 17,070 & 17,095 \\
IR length & 25,271 & 25,333 & 25,266 & 24,955 \\
Total gene number & 112 & 112 & 112 & 112 \\
No. of protein coding genes & 78 & 78 & 78 & 78 \\
No. of tRNA genes & 30 & 30 & 30 & 30 \\
No. of rRNA genes & 4 & 4 & 4 & 4 \\
GC content in genome (\%) & 37.7 & 37.7 & 37.7 & 37.7 \\
\hline
\end{tabular}




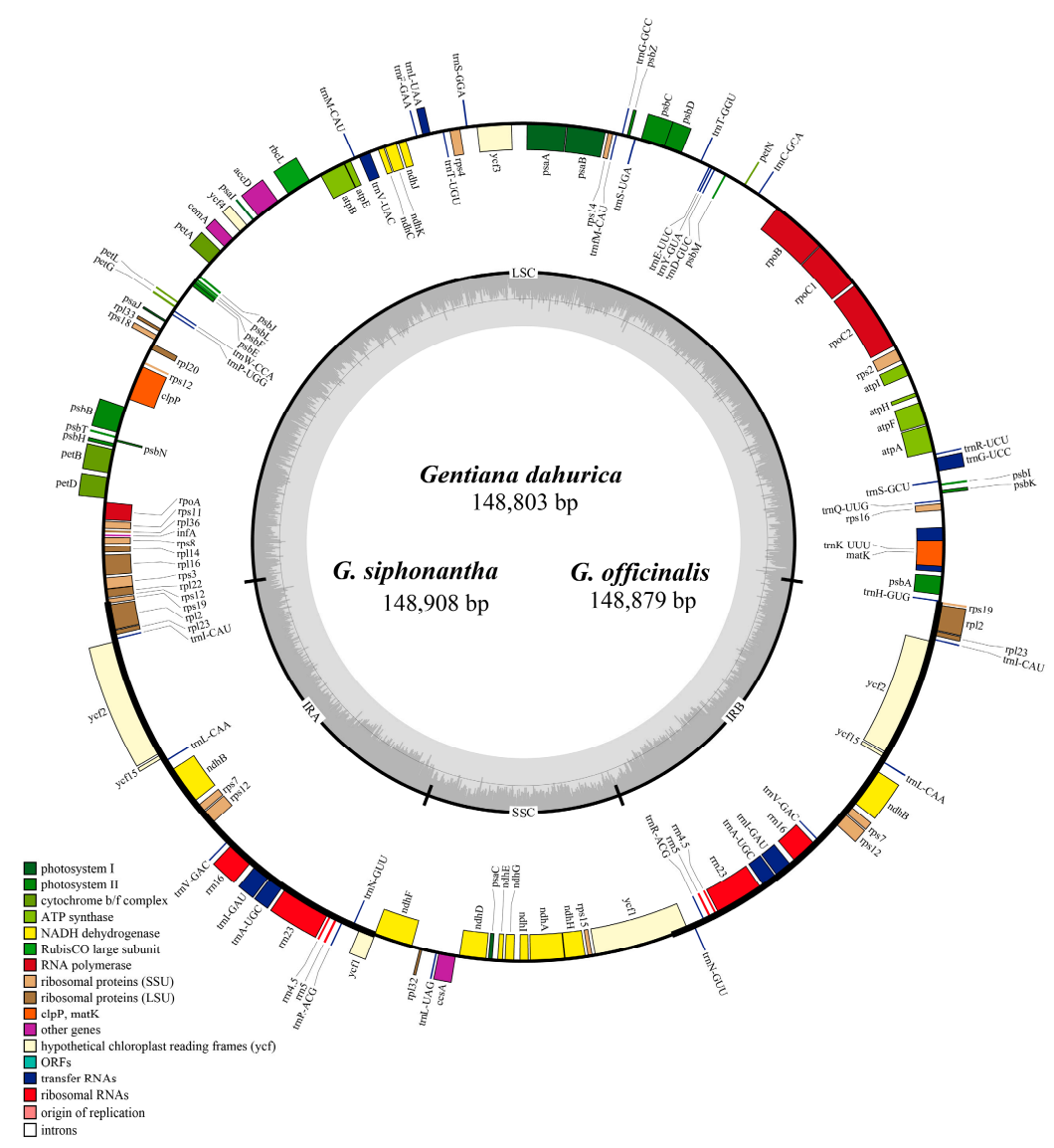

Figure 1. Merged gene map of the complete chloroplast genomes of three Gentiana species. Genes belonging to different functional groups are classified by different colors. The genes drawn outside of the circle are transcribed counterclockwise, while those inside are clockwise. Dashed area in the inner circle represent GC content of chloroplast genome.

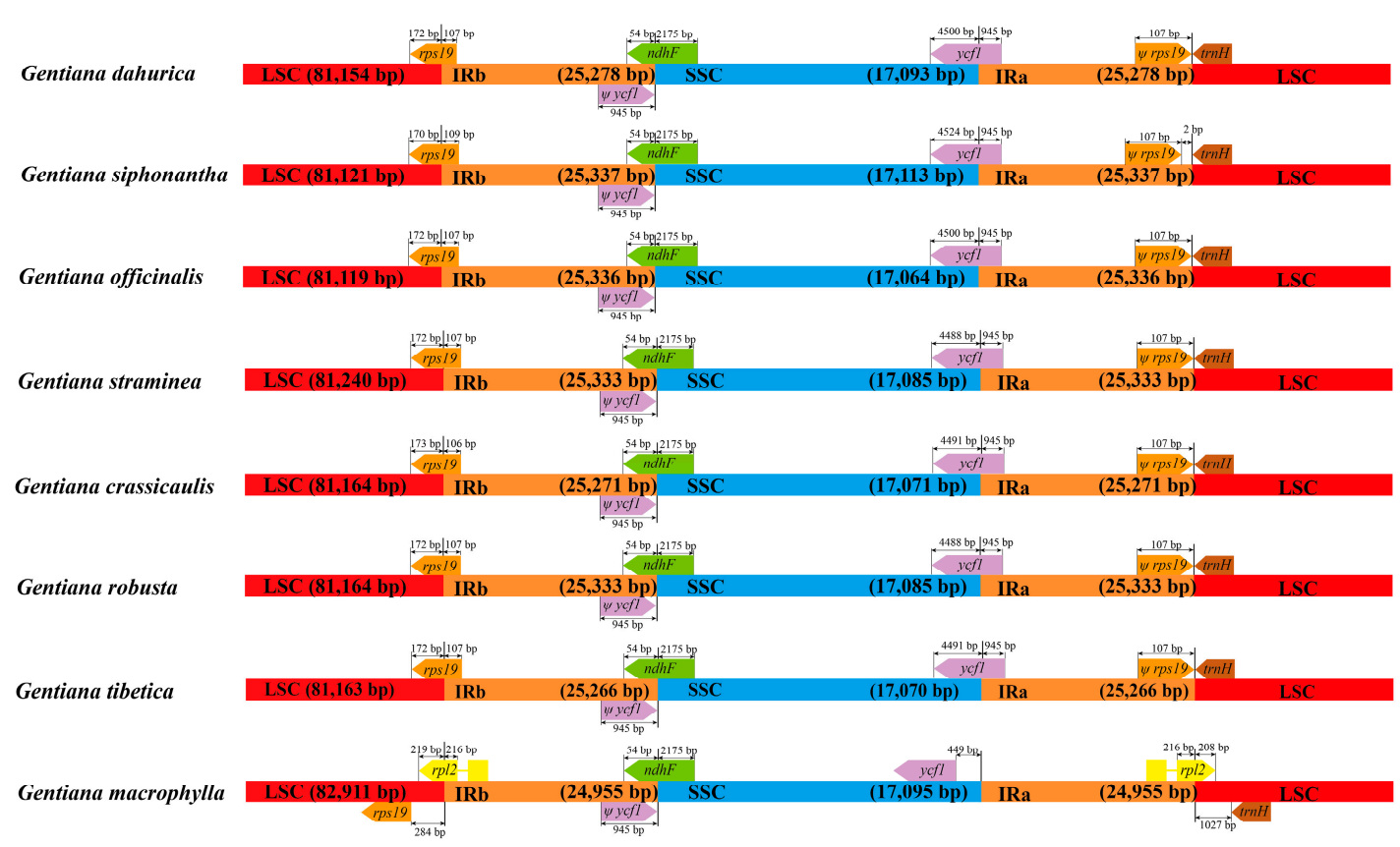

Figure 2. Comparison of chloroplast genome borders of LSC, SSC, and IRs among eight species in Gentiana sect. Cruciata. $\Psi$ indicates a pseudogene. 


\subsection{Comparative Analyses of the Chloroplast Genomes of Species of Sect. Cruciata}

Repeat analyses of three newly sequenced cp genomes showed 13/13/13 (G. siphonantha/ G. officinalis/G. dahurica) palindromic repeats, 12/11/11 dispersed repeats, and 7/6/6 tandem repeats (Figure $3 \mathrm{~A}, \mathrm{~B}$ ) with the repeat length range from 15 to $38 \mathrm{bp}$ (Tables S1 and S2). The numbers and distribution of all repeat types were similar and conserved in these three cp genomes. Overall, 32/30/30 repeats were detected in three cp genomes. Similarly, 37, 34, 34, and 37 repeats were found in previously reported G. crassicaulis, G. robusta, G. straminea, and G. tibetica cp genomes (Figure 3A,B). Unexpectedly, 61 repeats, including 28 dispersed repeats, 18 palindromic repeats and 15 tandem repeats, were found in the cp genome of G. macrophylla. We found most of repeats in eight cp genomes were located in the intergenic or intron regions, and only a few repeats were distributed in protein-coding regions $(y c f 1, y c f 2$, and $p s a A$ ) (Tables S1 and S2). Simple sequence repeats (SSRs) consisting of 1-6 bp repeat unit are distributed throughout the genome. In our study, perfect SSRs in eight Gentiana cp genomes were detected. The results showed that Mono-nucleotide repeats were most abundant type, followed by Tetra-nucleotides, Di-nucleotides and Tri-nucleotides. The penta- and hexa-nucleotides were very rare across the cp genomes (Figure 3C,D). Most SSRs are located in intergenic regions, but some were found in $r p o C 2, r p o C 1, a t p B, n d h F$, and ycf1 coding genes (Table S3). To investigate the evolutionary characteristics of cpDNA genes in eight Gentiana cp genomes and estimate selection pressures, nonsynonymous $(\mathrm{dN})$, synonymous substitution rates (dS), and the ratio of $\mathrm{dN} / \mathrm{dS}$ were calculated for 78 protein-coding genes (Table S4). We obtained 771 pairwise comparison results of $\mathrm{dN} / \mathrm{dS}$ values and the remaining could not be calculated due to $\mathrm{dS}=0$. Only four genes $(a c c D, c l p P$, mat $K$, and $y c f 1)$ had $\mathrm{dN} / \mathrm{dS}$ values $\geq 1$ indicating that they had undergone positive selection.
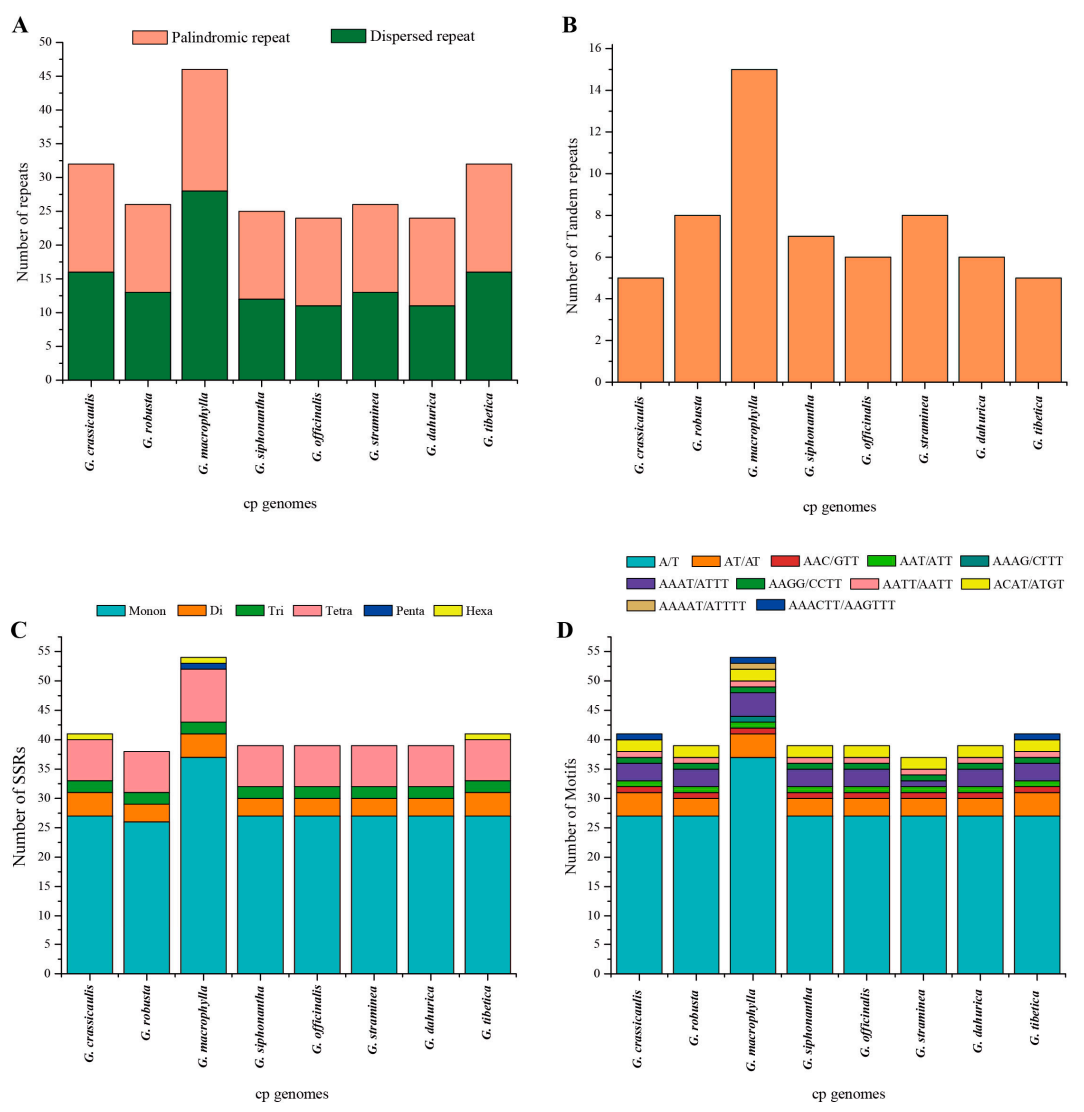

Figure 3. Analysis of different repeats in eight chloroplast genomes of Gentiana sect. Cruciata. (A) Histogram showing the number of palindromic repeats and dispersed repeats; (B) histogram showing the number of tandem repeats; (C) number of different simple sequence repeat (SSR) types detected in eight chloroplast genomes; (D) total numbers of different SSR motifs in eight chloroplast genomes. 
To understand the level of sequence divergence, comparative analysis among eight Gentiana cp genomes was performed using mVISTA with the annotation of $G$. crassicaulis as a reference. The $c p$ genomes within sect. Cruciata showed high sequence similarities with identities of only a few regions below $90 \%$, indicating a high conservatism of these chloroplast genomes (Figure 4). The single-copy regions and intergenic regions were more divergent than the IR regions and genic regions (Figure 5). According to the comparative analyses, some hotspot regions for genome divergence that could be utilized as potential genetic markers to elucidate the phylogenies and to discriminate the species in sect. Cruciata. These regions were $p s b A-t r n H, t r n K-r p s 16, r p s 16-t r n Q, \operatorname{trnS}-\operatorname{trn} G, \operatorname{trnE-trnT,} p s b M-\operatorname{trn} D, \operatorname{trn} T-p s b D, \operatorname{trnS}-p s b Z, n d h C-\operatorname{trn} V$, $a t p B-r b c L, r b c L-a c c D, a c c D-p s b I, r p l 33-r p s 18$, trnR-trnA, and trnV-rps7 (Figure 4).

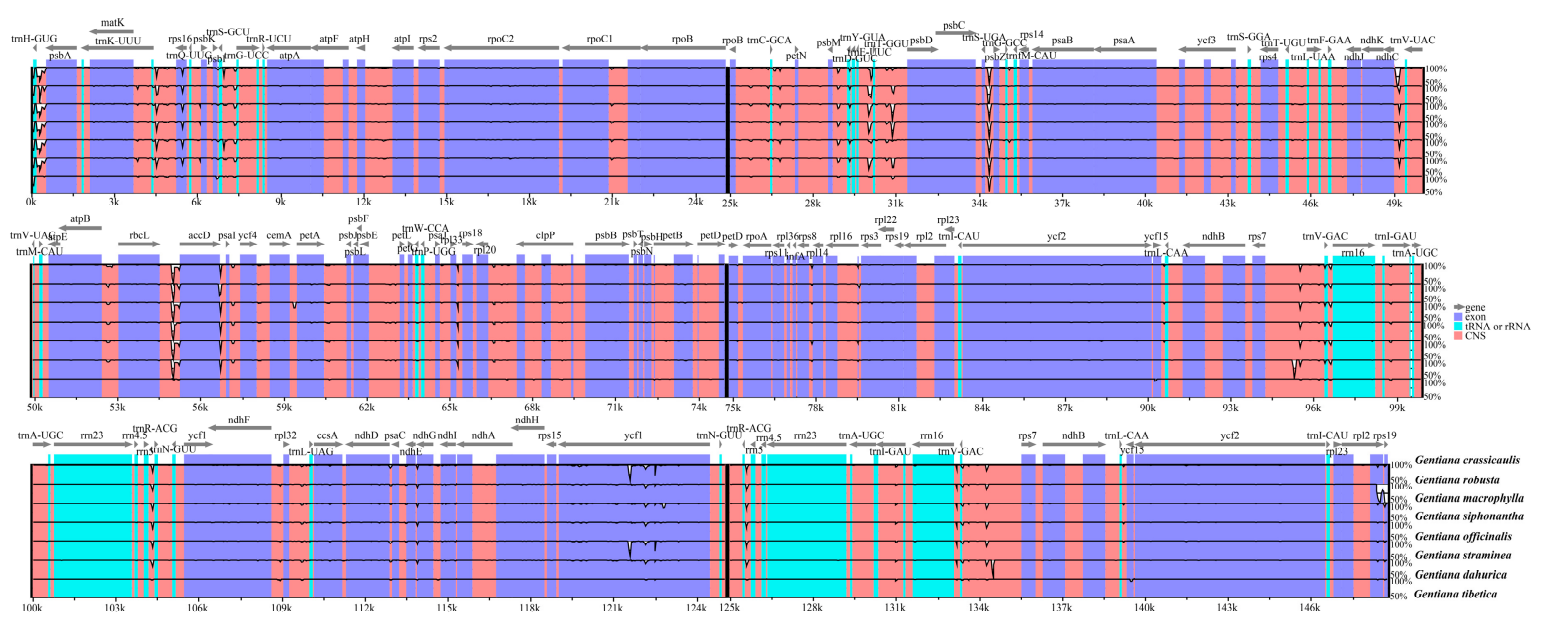

Figure 4. mVISTA percent identity plot comparing the eight chloroplast genomes of Gentiana sect. Cruciata with G. crassicaulis as a reference. The $y$-axis represents the percent identity within $50-100 \%$. Genome regions are color-coded as protein coding (purple), rRNA, or tRNA coding genes (blue), and noncoding sequences (pink).
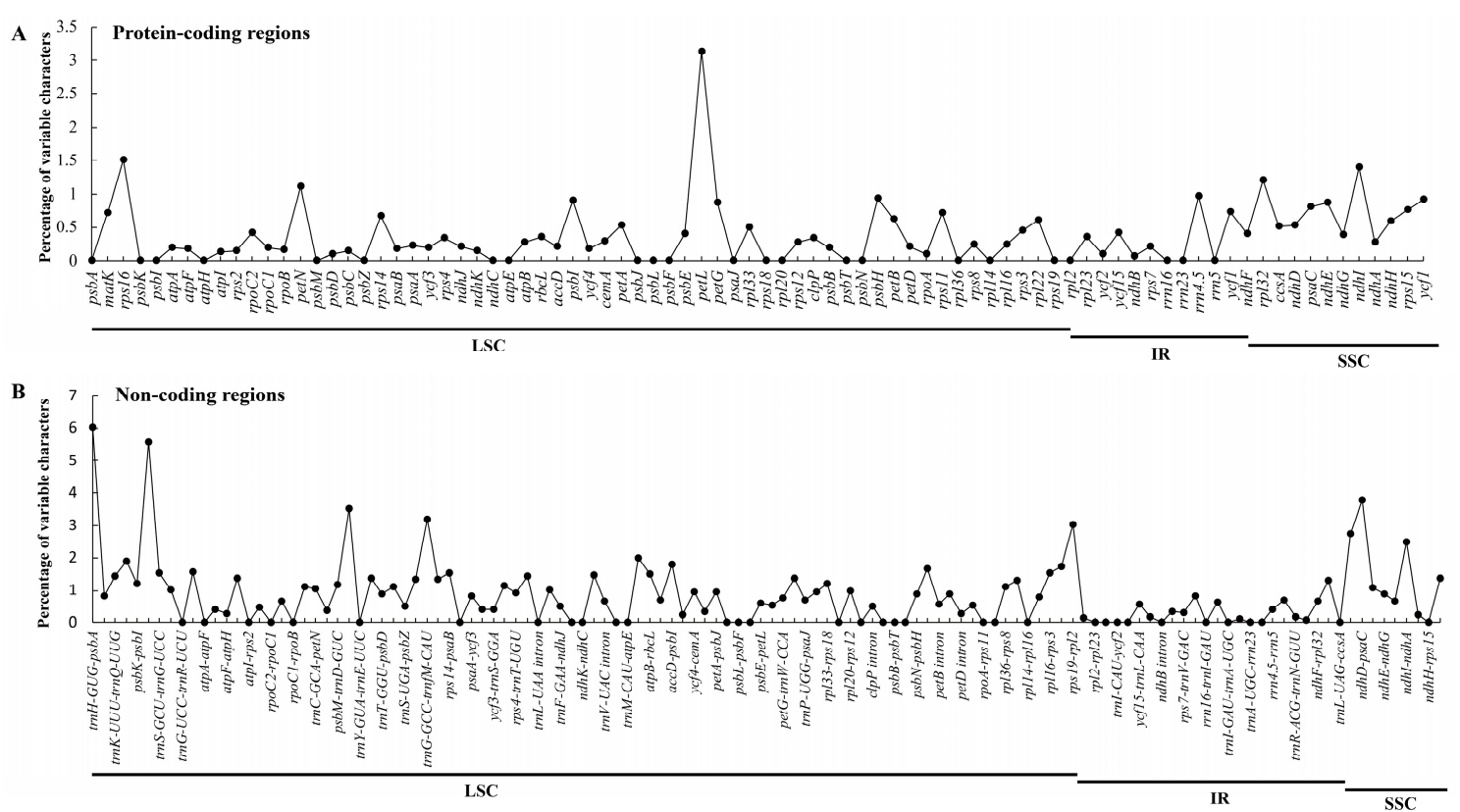

Figure 5. Percentage of variable characters in eight aligned chloroplast genomes of Gentiana sect. Cruciata. (A) Coding region; (B) Noncoding region. 


\subsection{Development of InDel Markers to Discriminate Species of Sect. Cruciata}

Based on the alignment of complete cp genome sequences, the 16 most InDel-variable loci were selected as candidate DNA markers for authentication (Table S5). After PCR amplification, these 16 markers could successfully amplify the expected polymorphic band sizes (Figure 6). Some of these 16 markers had unique amplicon sizes specific to different Gentiana species (Figure 6). Especially five markers (QJcpm9, QJcpm12, QJcpm14, QJcpm15, and QJcpm16) were specific to G. crassicaulis, which all derived from long InDels in the intergenic regions including rps16-trnQ, $p s b M-t r n D$, trnS-psbZ, accD-psbI, and trnK-rps16. The marker QJcpm1 was specific to G. robusta and G. crassicaulis and was derived from a 54 and $64 \mathrm{bp}$ InDel in the $n d h C-t r n V$ region. The QJcpm2 marker derived from 14 bp tandem repeat (TR) in cemA-petA region was specific to G. siphonantha and G. crassicaulis. QJcpm3 marker, which was specific to G. officinalis and G. crassicaulis, was derived from 72, $14 \mathrm{bp}$ InDels, and $7 \mathrm{bp}$ TR in $r b c L$-accD region. Three markers (QJcpm4, QJcpm10, and QJcpm11) were specific to G. straminea, G. robusta, and G. crassicaulis. QJcpm4 marker was derived from $12 \mathrm{bp}$ InDels and $6 \mathrm{bp}$ TR in the rpl33-rps18 region; QJcpm10 marker was derived from $9 \mathrm{bp}$ TR and $33 \mathrm{bp}$ InDel in the trnT-psbD; QJcpm11 marker was derived from $18 \mathrm{bp}$ InDel in rrn5-trnA region. The QJcpm5 marker, which was derived from 14,4 , and $7 \mathrm{bp}$ TR in atpB-rbcL, was specific to G. macrophylla, G. robusta, and G. crassicaulis. Three markers QJcpm6, QJcpm8, and QJcpm13 were derived from a 42 bp InDel in ycf1, 9 bp InDel in rps8-rpl14 region, and 24 bp TR in the trnS-trnG region, respectively, and were specific to G. straminea and G. robusta. The marker QJcpm7, which was specific G. dahurica and G. siphonantha, was also derived from 24 InDel in ycfl CDS region. Our validation results indicated all these markers can be used to identify species in sect. Cruciata.

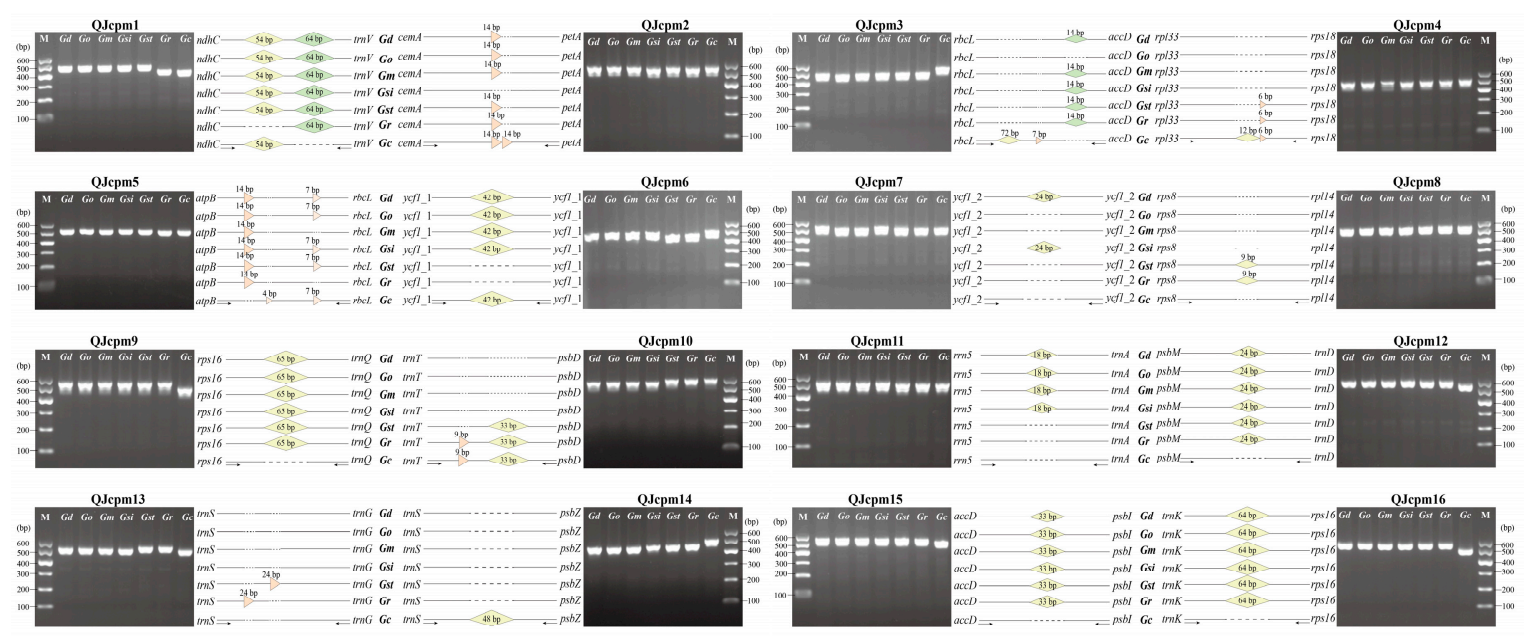

Figure 6. Validation of 16 molecular markers derived from InDel regions of eight chloroplast genomes of Gentiana sect. Cruciata. Inserted sequences and tandem repeats are designated by diamonds and triangle, respectively. Solid and dotted lines indicate conserved and deleted sequences, respectively. Left and right black arrows indicate forward and reverse primers, respectively. Abbreviated species names were shown on schematic diagrams: Gd, G. dahurica; Go, G. officinalis; Gm, G. macrophylla; Gsi, G. siphonantha; Gst, G. straminea; Gr, G. robusta; Gc, G. crassicaulis; M, D600 DNA ladder.

\subsection{Phylogenetic Relationships of Species Belong to Sect. Cruciata}

Here, $27 \mathrm{cp}$ genomes were retrieved to infer the interspecific relationships of eight species in sect. Cruciata as well as to clarify the phylogenetic relationships of some Gentianales species (Table S6). Phylogenetic analyses were performed using Maximum parsimony (MP), Maximum likelihood (ML) and Bayesian inference (BI) methods, and Arabidopsis thaliana was set as outgroup. Three different datasets including complete cp genomes, 70 shared protein-coding genes (PCGs) and the most conserved regions (TMCRs) of cp genomes were used to construct the phylogenetic trees. The results showed the same phylogenetic signals for these three datasets and the phylogenetic trees inferred from MP/ML/BI 
methods also shared identical topologies (Figure 7, Figures S2 and S3). In these phylogenetic trees, we found all the species of sect. Cruciata formed a monophyletic clade a with high bootstrap and BI support values and clustered with another two Gentianaceae species (G. lawrencei and Swertia mussotii) in the same clade $[29,30]$. Of these species, G. macrophylla, G. officinalis, and G. siphonantha showed paraphyletic relationships with each other and formed a monophyletic clade with G. dahurica. G. tibetica and G. crassicaulis formed a monophyletic clade and located in the basal position of these eight species in sect. Cruciata. Interestingly, G. robusta and G. straminea with similar morphological characteristics were clustered in a monophyletic clade with a high resolution value. In addition, our phylogenetic results supported the monophyly of two families, including Apocynaceae and Rubiaceae, in the order Gentianales. Unexpectedly, Gynochthodes nanlingensis (Morinda nanlingensis) belongs to Rubiaceae was embed in the Apocynaceae species.

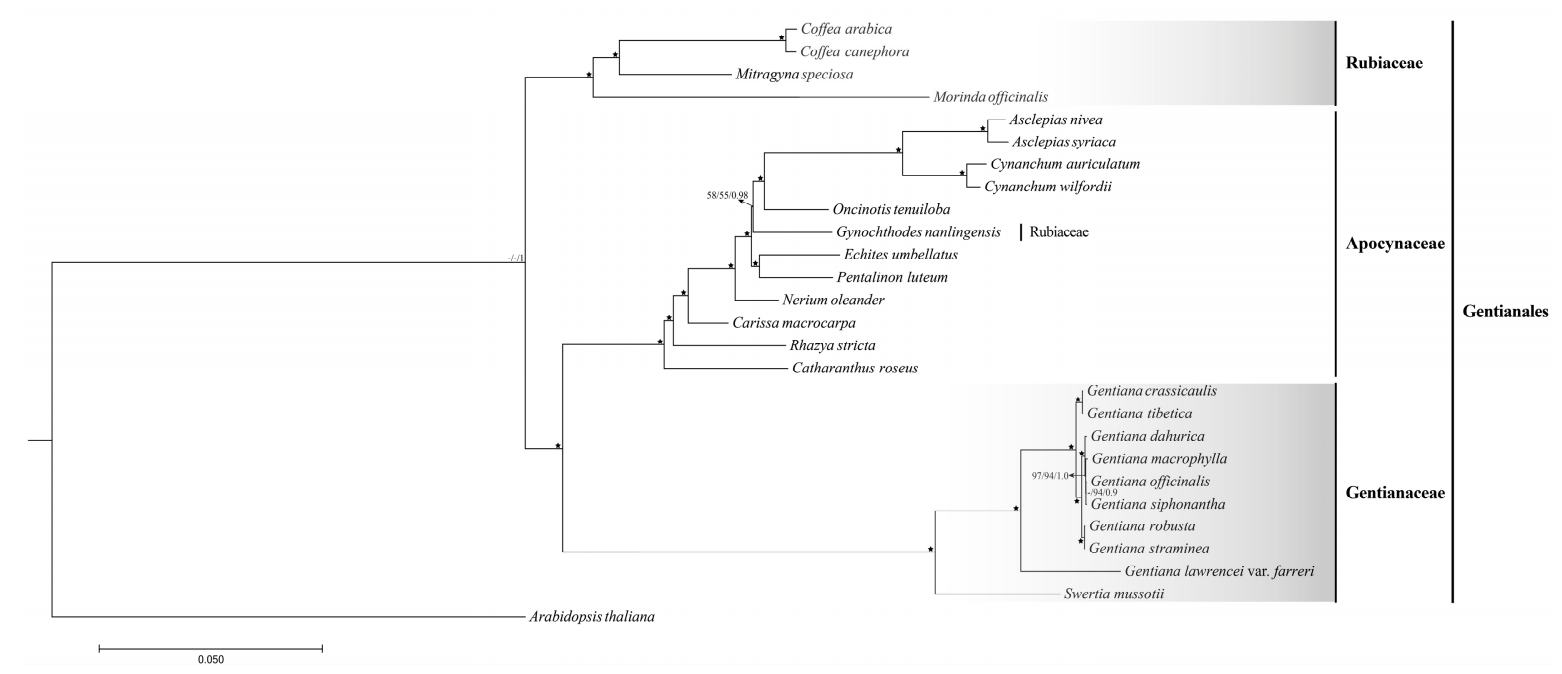

Figure 7. Phylogenetic relationships of species belong to Gentiana sect. Cruciata inferred from MP/ML/BI analysis based on complete chloroplast genome sequences. The numbers associated with each node are bootstrap support and posterior probability values, and the symbol $\star$ in the phylogenetic tree indicated that the support value of branch is $100 / 100 / 1.0$.

\section{Discussion}

Three cp genomes of sect. Cruciata were sequenced using Illumina Hiseq platform, which provided more resources for evolutionary and genetics studies of Gentiana. The cp genomic information presented in this study will also contribute to the conservation and management of wild resources of sect. Cruciata. Although a recent research reported that 11 ndh genes had been lost in the cp genomes of Gentiana sect. Kudoa [31], eight cp genomes of sect. Cruciata analyzed in present study are rather conserved in gene structures, contents and arrangement, and no significant structural rearrangements, such as inversions or gene relocations, were detected. Of these eight species, G. macrophylla has the largest cp genome size and other species showed minor differences in genome size. The length variations of these $\mathrm{cp}$ genomes may result from the length of intergenic regions, similar result has been reported for Paris (Melanthiaceae) cp genomes [18].

All the eight cp genomes of sect. Cruciata had the same protein-coding genes, tRNA and rRNA genes. We found that exon 2 of rps16 gene was lost in three newly sequenced cp genomes, and $r p s 16$ in other cp genomes also showed same structure. Therefore, rps16 pseudogene may commonly exist in the genus Gentiana [26]. And infA gene, which contains internal stop codons, was also inferred as pseudogene in these species. This pseudogene had been reported in many species [32-35]. Except for cp genome of G. macrophylla, the remained cp genomes showed minor variations in the junctions between the SSC and IRs regions. As most species of sect. Cruciata derived from a common radiation 
and usually showed closely interspecific relationships, we thus speculated that highly conserved nature of cp genomes resulted in the similar gene distributions at SC/IR boundaries.

Repeat structure plays an important role in genomic rearrangement, recombination, and sequence divergence in plastomes [36-38]. In the present study, cp genome of G. macrophylla has the largest number of repeats, while the number of repeats was similar in other $\mathrm{cp}$ genomes. Most of the repeated regions in different species showed similar characteristics and most repeats were located in intergenic regions or in ycf1/pasA. Repeats in these genes are commonly observed in other angiosperm lineages $[22,32,39]$. Cp microsatellites (cpSSR) usually showed high polymorphism within the same species and which are potentially useful markers for population genetics [40]. Here, 326 SSRs varying in number and type between eight major Gentiana species, and the most abundant repeat type was found to be stretches of mononucleotides (A/T). Similar to the distribution status of dispersed and tandem repeats, most cpSSRs were observed in noncoding regions, and only small proportion were found in coding regions. CPSSRs located in noncoding regions of the cp genome are generally short mononucleotide tandem repeats and commonly showed intraspecific variation in repeat number [15]. Therefore, cpSSRs derived from eight Gentiana species in this study are expected to be useful for the genetic diversity studies in Gentiana. As the wild resources of some Gentiana species were dramatically declined due to overexploitation, we thought these species need to transplant or cultivate in order to preserve their germplasm resources. We believe the obtained SSRs among these chloroplast genomes will also be useful for the domestication and breeding of Gentiana species.

Sequence divergence of the coding genes was observed between different species. Our analyses indicated that all of $\mathrm{cp}$ genes showed a low sequence divergence $(\mathrm{dS}<0.1)$ and most cp genes were under purifying selection $(\mathrm{dN} / \mathrm{dS}<1)$; similar results were reported for other $\mathrm{cp}$ genomes $[32,41,42]$. Only four genes $(a c c D, c l p P$, matK, and $y c f 1)$ were under positive selection. Previous research reported that $a c c D$ and $\operatorname{clpP}$ genes had a high evolution rate in Fagopyrum species [43,44], we thus presumed that these genes may have a high evolution rate in Gentiana species. One other gene (matK) was highly divergent in Caryophyllaceae, and comparative cp genomes analyses of Myrtaceae also indicated matK was under positive pressure [45,46]. The ycf1 gene with unknown functions showed a biased higher value for $\mathrm{dN} / \mathrm{dS}$ ratio compared to $\mathrm{dS}$ value indicating that this gene evolved at a faster rate. It has also been shown to be subject to positive selection in many angiosperms [20,22,32,44,45].

DNA barcodes are defined as the short DNA sequences with a sufficiently high mutation rate to discriminate a species within a given taxonomic group and are confirmed as reliable tools for the identification of plant species [16,47]. Previously, $r b c L, t r n H-p s b A$, and matK were considered as "core" plant barcodes for species identification, but they often have limited resolutions at species level [18]. Previous research showed that three commonly used barcodes in some cases may not be suitable to authenticate the medicinal plant in section Cruciata $[24,25]$. Therefore, seeking for more effective DNA barcodes with high evolutionary rates is very important for the molecular identification of species in Gentiana sect. Cruciata. The complete cp genome has a conserved sequence from $110 \mathrm{k}$ to $160 \mathrm{k} \mathrm{bp}$, which far exceeds the length of commonly used molecular markers and provides more variation to distinguish closely related species $[12,16]$. Therefore, some mutation hotspot regions, including trnK-rps16, rps16-trnQ, trnS-trnG, trnE-trnT, trnT-psbD, trnS-psbZ, ndhC-trnV, rbcL-accD, accD-psbI, $\operatorname{trnR} \operatorname{trn} A, \operatorname{trn} V$-rps7, and $y c f 1$, detected from the cp genomes can provide more specific DNA barcodes for the authentication of medicinal materials of sect. Cruciata and also provide sufficient genetic markers for resolving the phylogeny of Gentianaceae.

We developed the specific markers for species authentication of sect. Cruciata based on the hotspot regions derived from cp genomes. Most of these markers were derived from the intergenic regions of cp genomes and showed high interspecific polymorphism. Previous molecular identification of Panax, Zanthoxylum, and Eclipta species also indicated that chloroplast-derived genetic markers had high discriminatory powers $[12,14,48]$. Therefore, specific markers developed from the comparative $c p$ genomes were superior than the commonly used markers for identifying the closely related species. Especially for medicinal plants, these specific genetic markers are more effective in the authentication 
of their source plants. We found two InDels (42 and $24 \mathrm{bp}$ ) in the ycf1 gene, which can be used to distinguish species in sect. Cruciata. Ycf1, which encodes a protein of approximately 1800 amino acids with unknown function, is the second largest gene in the $\mathrm{cp}$ genome. Because the sequence of $y c f 1$ is too long and too variable for designing universal primers, it has received little attention for DNA barcodes at low taxonomy [18,49]. But two markers derived from ycf1 gene showed high PCR efficiency and polymorphism in species of sect. Cruciata, and could be used as specific barcodes for the authentication of Gentiana species. Although our study provided 16 genetic markers which had enough interspecies polymorphism for species identification, some of the markers were usually specific to two species. We thus suggest a combination of several markers should be considered for credible authentication between different species in genus Gentiana.

We inferred the phylogenetic relationships of sect. Cruciata using complete cp genomes. Three different methods (MP/ML/BI) were used to rebuilt the phylogenetic trees based on different datasets (cp genomes, 70 shared PCGs, and TMCRs), and the derived phylogenetic trees shared identical topology. All the species of sect. Cruciata formed a monophyletic clade with high bootstrap and BI support values. This result is comparable with the previous phylogenetic research based on four cpDNA fragments [1]. Four species, including G. dahurica, G. macrophylla, G. siphonantha, and G. officinalis, were clustered in the same clade with high support values. Although the flower color of G. officinalis was different from other three species, it shared similar morphological and chemical characters with G. macrophylla [50]. We found that G. straminea was closely related to G. robusta. G. robusta may have originated from introgression between G. straminea and another relative species, and these two species are usually closer to each other [26,51]. Two species, G. tibetica and G. crassicaulis were clustered in the same clade and located in the basal position in the clade of sect. Cruciata. However, a previous phylogenetic result indicated that G. tibetica was closely related to G. straminea and G. robusta [1]. As G. tibetica and G. crassicaulis distributed sympatrically in Tibet and intermediate types were produced by introgression between these two species [52], we thus inferred these two species should be closely related. In addition, based on the phylogenetic results, we found that the family Gentianaceae was closer to family Apocynaceae than to family Rubiaceae in order Gentianales. Previous phylogenetic studies of order Gentianales resulted in similar findings, but with relatively low support values [53,54]. Although our result confirmed the monophyly of section Cruciata and primarily elucidated the phylogeny of Gentianales based on available cp genomes, more complete $\mathrm{cp}$ genome sequences are needed to resolve the comprehensive phylogenies of this section, especially since limited taxon sampling may produce discrepancies in tree topologies [15,55].

\section{Materials and Methods}

\subsection{Plant Materials and DNA Isolation}

Samples of G. dahurica, G. siphonantha and G. officinalis were collected from Tianzhu (102.54 E, $\left.37.01^{\circ} \mathrm{N}\right)$, Sunan $\left(98.05^{\circ} \mathrm{E}, 39.55^{\circ} \mathrm{N}\right)$ and Yuzhong $\left(104.05^{\circ} \mathrm{E}, 35.78^{\circ} \mathrm{N}\right)$ Counties in Gansu Province, China. Young leaves of three species were collected and immediately dried with silica gel for further DNA isolation. Total genomic DNA was isolated from each sample using the modified Cetyl Trimethyl Ammonium Bromide (CTAB) method [56]. The quantity and quality of extracted genomic DNA was determined by gel electrophoresis and NanoDrop 2000 Spectrophotometer (Thermo Scientific, Carlsbad, CA, USA).

\subsection{Chloroplast Genome Sequencing, Assembly and Annotation}

The DNA Library with insert size of $200 \mathrm{bp}$ was prepared according to the description by Zhou et al. [32], and sequenced using Illumina Hiseq ${ }^{\mathrm{TM}} 2500$ platform (Illumina Inc., San Diego, CA, USA) with the average read length of $125 \mathrm{bp}$. The obtained raw reads were filtered with the NGS QC Toolkit_v2.3.3 (National Institute of Plant Genome Research, New Delhi, India) [57]. Adapter sequences and low-quality reads with Q-value $\leq 20$ were removed. Filtered paired-end reads were firstly mapped to the chloroplast genome of Gentiana straminea (KJ657732) by using the Bowtie 2-2.2.6 (University of Maryland, 
College Park, MD, USA.) with default parameter [58]. And then the matched paired-end reads were de novo assembled using SPAdes-3.6.0 (St. Petersburg Academic University, St. Petersburg, Russia) [59]. After de novo assembly, the resultant scaffolds were further assembled using a baiting and iteration method based on Perl script MITObim_1.9.pl (University of Oslo, Oslo, Norway) [60]. Finally, all obtained reads were mapped to the spliced cp genome sequence using Geneious 10.1 (Biomatters Ltd., Auckland, New Zealand) in order to avoid assembly errors. The four junction regions between the IRs and SSC / LSC were confirmed by PCR amplification and Sanger sequencing (Primers and sequencing results are listed in Table S7). The cp genome genes were annotated with the online program Organellar Genome Annotator (DOGMA) [61], and the primary annotated results were manually verified according to the annotation information from other closely related species. The circular plastid genome maps were drawn using the online program OrganellarGenome DRAW (Max planck Institute of Molecular Plant Physiology, Potsdam, Germany) [62] and three newly sequenced cp genome were deposited in GenBank (MH261259-MH261261).

\subsection{Repeat Structure, Genome Comparison and Sequence Divergence}

Dispersed and palindromic repeats within the $\mathrm{cp}$ genomes were identified using REPuter (University of Bielefeld, Bielefeld, Germany) with a minimum repeat size of $30 \mathrm{bp}$ and a sequence identity $>90 \%$ [63]. Tandem repeat sequences were searched using the Tandem Repeats Finder program (Mount Sinai School of Medicine, New York, NY, USA) with the following parameters: 2 for alignment parameters match, 7 for mismatch and InDel, respectively [64]. Simple sequence repeats (SSRs) were predicted using MISA perl script (Institute of Plant Genetics and Crop Plant Research, Gatersleben, Germany) with the parameters of ten for mono, five for di-, four for tri-, and three for tetra-, penta, and hexa-nucleotide motifs [65]. The nonsynonymous ( $\mathrm{dN})$, synonymous (dS), and $\mathrm{dN} / \mathrm{dS}$ values of each protein coding gene were calculated using PAML packages 4.0 (University College London, London, UK) with Yang and Nielsen (YN) algorithm to detect whether selective pressure exists for plastid genes [66]. The cp genome gene distribution of eight Gentiana species was compared and visualized using mVISTA software with the annotation of $G$. crassicaulis as a reference [67]. To examine mutation hotspot regions of the cp genomes of eight Gentiana species, the percentages of variable characters for each coding and noncoding regions were analyzed using the method described by Zhang et al. [68].

\subsection{Development and Validation of the InDel Molecular Marker}

In order to validate interspecies polymorphisms within the chloroplast genomes and develop DNA genetic markers for identifying species belong to sect. Cruciata, specific primers were designed using Primer 3 based on the mutational hotspot regions found in these Gentiana chloroplast genomes [69]. PCR amplifications were performed in a reaction volume of $25 \mu \mathrm{L}$ with $12.5 \mu \mathrm{L} 2 \times$ Taq PCR Master Mix, $0.4 \mu \mathrm{M}$ of each primer, $2 \mu \mathrm{L}$ template DNA and $10.1 \mu \mathrm{L} \mathrm{ddH}_{2} \mathrm{O}$. All amplifications were carried out in SimpliAmp ${ }^{\text {TM }}$ Thermal Cycler (Applied Biosystems, Carlsbad, CA, USA) as follow: denaturation at $94{ }^{\circ} \mathrm{C}$ for $5 \mathrm{~min}$, followed by 30 cycles of $94{ }^{\circ} \mathrm{C}$ for $50 \mathrm{~s}$, at specific annealing temperature (Tm) for $40 \mathrm{~s}, 72{ }^{\circ} \mathrm{C}$ for $90 \mathrm{~s}$ and $72{ }^{\circ} \mathrm{C}$ for $7 \mathrm{~min}$ as final extension. PCR products were visualized on $2 \%$ agarose gels after staining with ethidium bromide and then the DNA fragments were sequenced by Sangon Biotech (Shanghai, China) (Sequencing results are listed in Table S8).

\subsection{Phylogenetic Analysis}

The complete chloroplast genomes of 26 Gentianales species were recovered to clarify the phylogenetic relationships of sect. Cruciata and the cp genome of Arabidopsis thaliana was set as outgroup. In order to obtain a reliable result, phylogenetic analyses were implemented based on different $\mathrm{cp}$ genome datasets. On the one hand, whole $\mathrm{cp}$ genome sequences and 70 common $\mathrm{cp}$ protein-coding genes (PCGs) were separately used to infer the phylogenetic relationships of these species. On the other hand, multi-gene alignment matrix, which contained the most conserved regions (TMCRs) of cp genome was generated using HomBlocks (Ocean University of China, Qingdao, China) [70], was used to understand the phylogenetic relationships at $\mathrm{cp}$ genome level. Alignments were constructed using 
MAFFT v7.308 (Osaka University, Suita, Japan) with default parameters and the best-fit nucleotide substitution model (General Time Reversible + Invariant + Gamma, GTR + I + G) was determined with Modeltest 3.7 (Brigham Young University, Provo, UT, USA) [71,72]. Maximum parsimony (MP) analyses of the resulting alignments from different datasets were performed using PAUP 4.0b10 (Smithsonian Institution, Washington, DC, USA) [73]. Maximum likelihood (ML) analyses were performed using RAxML 8.1.24 (Heidelberg Institute for Theoretical Studies, Heidelberg, Germany) with GTR + I + G nucleotide substitution model [74]. The reliability of each tree node was tested by bootstrap analysis with 1000 replicates. Bayesian analyses were also conducted with MrBayes v3.2.6 (Swedish Museum of Natural History, Stockholm, Sweden) [75] under the same substitution model (GTR + I + G). The Markov chain Monte Carlo (MCMC) algorithm was run for one million generations, with one tree sampled every 100 generations. The first $25 \%$ of trees were discarded as burn-in to construct majority-rule consensus tree and estimate posterior probabilities (PP) for each node.

Supplementary Materials: Supplementary materials can be found at http://www.mdpi.com/1422-0067/19/7/ 1962/s1.

Author Contributions: T.Z. and X.W. conceived and designed the work; T.Z. and J.W. collected samples; T.Z., J.W., Y.J., W.L., and F.X. performed the experiments and analyzed the data; T.Z. wrote the manuscript; X.W. revised the manuscript. All authors gave final approval of the paper.

Acknowledgments: This work was financially co-supported by the National Natural Science Foundation of China (31770364) and Scientific Research Supporting Project for New Teacher of Xi'an Jiaotong University (YX1K105).

Conflicts of Interest: The authors declare no conflict of interest.

\section{References}

1. Zhang, X.L.; Wang, Y.J.; Ge, X.J.; Yuan, Y.M.; Yang, H.L.; Liu, J.Q. Molecular phylogeny and biogeography of Gentiana sect. Cruciata (Gentianaceae) based on four chloroplast DNA datasets. Taxon 2009, 58, 862-870.

2. Ho, T.N.; Liu, S.W. A Worldwide Monograph of Gentiana; Science Press: Beijing, China, 2001.

3. Ho, T.N.; Pringle, S.J. "Gentianaceae," Flora of China; Science Press: Beijing, China, 1995; Volume 16, pp. 1-140.

4. State Pharmacopoeia Commission of the PRC. Pharmacopoeia of P.R. China, Part 1; Chemical Industry Publishing House: Beijing, China, 2015; pp. 270-271.

5. Hua, W.; Zheng, P.; He, Y.; Cui, L.; Kong, W.; Wang, Z. An insight into the genes involved in secoiridoid biosynthesis in Gentiana macrophylla by RNA-seq. Mol. Biol. Rep. 2014, 41, 4817-4825. [CrossRef] [PubMed]

6. Chang-Liao, W.-L.; Chien, C.-F.; Lin, L.-C.; Tsai, T.-H. Isolation of gentiopicroside from Gentianae Radix and its pharmacokinetics on liver ischemia/reperfusion rats. J. Ethnopharmacol. 2012, 141, 668-673. [CrossRef] [PubMed]

7. Yin, H.; Zhao, Q.; Sun, F.-M.; An, T. Gentiopicrin-producing endophytic fungus isolated from Gentiana macrophylla. Phytomedicine 2009, 16, 793-797. [CrossRef] [PubMed]

8. Yu, F.; Yu, F.; Li, R.; Wang, R. Inhibitory effects of the Gentiana macrophylla (Gentianaceae) extract on rheumatoid arthritis of rats. J. Ethnopharmacol. 2004, 95, 77-81. [CrossRef] [PubMed]

9. Li, X.; Wang, L.; Yang, H.; Liu, J. Confirmation of natural hybrids between Gentiana straminea and G. siphonantha (Gentianaceae) based on molecular evidence. Front. Biol. China 2008, 3, 470-476. [CrossRef]

10. Hu, Q.; Peng, H.; Bi, H.; Lu, Z.; Wan, D.; Wang, Q.; Mao, K. Genetic homogenization of the nuclear ITS loci across two morphologically distinct gentians in their overlapping distributions in the Qinghai-Tibet Plateau. Sci. Rep. 2016, 6, 34244. [CrossRef] [PubMed]

11. Zhao, Z.; Su, J.; Wang, Z. Pharmacognostical studies on root of Gentiana siphonantha. Chin. Tradit. Herbal Drugs 2006, 37, 1875-1878.

12. Nguyen, V.B.; Park, H.-S.; Lee, S.-C.; Lee, J.; Park, J.Y.; Yang, T.-J. Authentication markers for five major Panax species developed via comparative analysis of complete chloroplast genome sequences. J. Agric. Food Chem. 2017, 65, 6298-6306. [CrossRef] [PubMed]

13. Bendich, A.J. Circular chloroplast chromosomes: The grand illusion. Plant Cell 2004, 16, 1661-1666. [CrossRef] [PubMed]

14. Lee, H.J.; Koo, H.J.; Lee, J.; Lee, S.-C.; Lee, D.Y.; Giang, V.N.L.; Kim, M.; Shim, H.; Park, J.Y.; Yoo, K.-O.; et al. Authentication of Zanthoxylum species based on integrated analysis of complete chloroplast genome sequences and metabolite profiles. J. Agric. Food Chem. 2017, 65, 10350-10359. [CrossRef] [PubMed] 
15. Eguiluz, M.; Rodrigues, N.F.; Guzman, F.; Yuyama, P.; Margis, R. The chloroplast genome sequence from Eugenia uniflora, a Myrtaceae from Neotropics. Plant Syst. Evol. 2017, 303, 1199-1212. [CrossRef]

16. Li, X.; Yang, Y.; Henry, R.J.; Rossetto, M.; Wang, Y.; Chen, S. Plant DNA barcoding: From gene to genome. Biol. Rev. 2015, 90, 157-166. [CrossRef] [PubMed]

17. Hollingsworth, P.M.; Forrest, L.L.; Spouge, J.L.; Hajibabaei, M.; Ratnasingham, S.; van der Bank, M.; Chase, M.W.; Cowan, R.S.; Erickson, D.L.; Fazekas, A.J.; et al. A DNA barcode for land plants. Proc. Natl. Acad. Sci. USA 2009, 106, 12794-12797.

18. Song, Y.; Wang, S.; Ding, Y.; Xu, J.; Li, M.F.; Zhu, S.; Chen, N. Chloroplast genomic resource of Paris for species discrimination. Sci. Rep. 2017, 7, 3427. [CrossRef] [PubMed]

19. Ma, P.-F.; Zhang, Y.-X.; Zeng, C.-X.; Guo, Z.-H.; Li, D.-Z. Chloroplast phylogenomic analyses resolve deep-level relationships of an intractable bamboo tribe Arundinarieae (Poaceae). Systematic Biol. 2014, 63, 933-950. [CrossRef] [PubMed]

20. Carbonell-Caballero, J.; Alonso, R.; Ibañez, V.; Terol, J.; Talon, M.; Dopazo, J. A phylogenetic analysis of 34 chloroplast genomes elucidates the relationships between wild and domestic species within the genus Citrus. Mol. Biol. Evol. 2015, 32, 2015-2035. [CrossRef] [PubMed]

21. Dong, W.; Xu, C.; Li, W.; Xie, X.; Lu, Y.; Liu, Y.; Jin, X.; Suo, Z. Phylogenetic resolution in Juglans based on complete chloroplast genomes and nuclear DNA sequences. Front. Plant Sci. 2017, 8, 1148. [CrossRef] [PubMed]

22. Yang, Y.; Zhou, T.; Duan, D.; Yang, J.; Feng, L.; Zhao, G. Comparative analysis of the complete chloroplast genomes of five Quercus species. Front. Plant Sci. 2016, 7, 959. [CrossRef] [PubMed]

23. Huang, C.-Y.; Gruenheit, N.; Ahmadinejad, N.; Timmis, J.; Martin, W. Mutational decay and age of chloroplast and mitochondrial genomes transferred recently to angiosperm nuclear chromosomes. Plant Physiol. 2005, 138, 1723-1733. [CrossRef] [PubMed]

24. Liu, J.; Yan, H.-F.; Ge, X.-J. The use of DNA barcoding on recently diverged species in the genus Gentiana (Gentianaceae) in China. PLoS ONE 2016, 11, e0153008. [CrossRef] [PubMed]

25. Zhang, D.; Gao, Q.; Li, F.; Li, Y. DNA molecular identification of botanical origin in Chinese herb Qingjiao. J. Anhui Agric. Sci. 2011, 39, 14609-14612.

26. Ni, L.; Zhao, Z.; Xu, H.; Chen, S.; Dorje, G. Chloroplast genome structures in Gentiana (Gentianaceae), based on three medicinal alpine plants used in Tibetan herbal medicine. Curr. Genet. 2017, 63, 241-252. [CrossRef] [PubMed]

27. Ni, L.; Zhao, Z.; Xu, H.; Chen, S.; Dorje, G. The complete chloroplast genome of Gentiana straminea (Gentianaceae), an endemic species to the Sino-Himalayan subregion. Gene 2016, 577, 281-288. [CrossRef] [PubMed]

28. Wang, X.; Yang, N.; Su, J.; Zhang, H.; Cao, X. The complete chloroplast genome of Gentiana macrophylla. Mitochondrial DNA B 2017, 2, 395-396. [CrossRef]

29. Xiang, B.; Li, X.; Qian, J.; Wang, L.; Ma, L.; Tian, X.; Wang, Y. The complete chloroplast genome sequence of the medicinal plant Swertia mussotii using the PacBio RS II platform. Molecules 2016, 21, 1029. [CrossRef] [PubMed]

30. Fu, P.-C.; Zhang, Y.-Z.; Geng, H.-M.; Chen, S.-L. The complete chloroplast genome sequence of Gentiana lawrencei var. farreri (Gentianaceae) and comparative analysis with its congeneric species. PeerJ 2016, 4, e2540. [CrossRef] [PubMed]

31. Sun, S.-S.; Fu, P.-C.; Zhou, X.-J.; Cheng, Y.-W.; Zhang, F.-Q.; Chen, S.-L.; Gao, Q.-B. The complete plastome sequences of seven species in Gentiana sect. Kudoa (Gentianaceae): Insights into plastid gene loss and molecular evolution. Front. Plant Sci. 2018, 9, 493. [CrossRef] [PubMed]

32. Zhou, T.; Chen, C.; Wei, Y.; Chang, Y.; Bai, G.; Li, Z.; Kanwal, N.; Zhao, G. Comparative transcriptome and chloroplast genome analyses of two related Dipteronia Species. Front. Plant Sci. 2016, 7, 1512. [CrossRef] [PubMed]

33. Yang, J.-B.; Li, D.-Z.; Li, H.-T. Highly effective sequencing whole chloroplast genomes of angiosperms by nine novel universal primer pairs. Mol. Ecol. Resour. 2014, 14, 1024-1031. [CrossRef] [PubMed]

34. Hu, Y.; Woeste, K.E.; Zhao, P. Completion of the chloroplast genomes of five Chinese Juglans and their contribution to chloroplast phylogeny. Front. Plant Sci. 2016, 7, 1955. [CrossRef] [PubMed]

35. Sun, Y.; Moore, M.J.; Zhang, S.; Soltis, P.S.; Soltis, D.E.; Zhao, T.; Meng, A.; Li, X.; Li, J.; Wang, H. Phylogenomic and structural analyses of 18 complete plastomes across nearly all families of early-diverging eudicots, including an angiosperm-wide analysis of IR gene content evolution. Mol. Phylogenet. Evol. 2016, 96, 93-101. [CrossRef] [PubMed] 
36. Weng, M.-L.; Blazier, J.C.; Govindu, M.; Jansen, R.K. Reconstruction of the ancestral plastid genome in Geraniaceae reveals a correlation between genome rearrangements, repeats and nucleotide substitution rates. Mol. Biol. Evol. 2013, 31, 645-659. [CrossRef] [PubMed]

37. Lu, L.; Li, X.; Hao, Z.; Yang, L.; Zhang, J.; Peng, Y.; Xu, H.; Lu, Y.; Zhang, J.; Shi, J.; et al. Phylogenetic studies and comparative chloroplast genome analyses elucidate the basal position of halophyte Nitraria sibirica (Nitrariaceae) in the Sapindales. Mitochondrial DNA A 2017, 1-11. [CrossRef] [PubMed]

38. Asano, T.; Tsudzuki, T.; Takahashi, S.; Shimada, H.; Kadowaki, K. Complete nucleotide sequence of the sugarcane (Saccharum officinarum) chloroplast genome: A comparative analysis of four monocot chloroplast genomes. DNA Res. 2004, 11, 93-99. [CrossRef] [PubMed]

39. Curci, P.L.; De Paola, D.; Danzi, D.; Vendramin, G.G.; Sonnante, G. Complete chloroplast genome of the multifunctional crop globe artichoke and comparison with other asteraceae. PLoS ONE 2015, 10, e0120589. [CrossRef] [PubMed]

40. Provan, J.; Powell, W.; Hollingsworth, P.M. Chloroplast microsatellites: New tools for studies in plant ecology and evolution. Trends Ecol. Evol. 2001, 16, 142-147. [CrossRef]

41. Rousseau-Gueutin, M.; Bellot, S.; Martin, G.E.; Boutte, J.; Chelaifa, H.; Lima, O.; Michon-Coudouel, S.; Naquin, D.; Salmon, A.; Ainouche, K. The chloroplast genome of the hexaploid Spartina maritima (Poaceae, Chloridoideae): Comparative analyses and molecular dating. Mol. Phylogenet. Evol. 2015, 93, 5-16. [CrossRef] [PubMed]

42. Xu, J.-H.; Liu, Q.; Hu, W.; Wang, T.; Xue, Q.; Messing, J. Dynamics of chloroplast genomes in green plants. Genomics 2015, 106, 221-231. [CrossRef] [PubMed]

43. Yamane, K.; Yasui, Y.; Ohnishi, O. Intraspecific cpDNA variations of diploid and tetraploid perennial buckwheat, Fagopyrum cymosum (Polygonaceae). Am. J. Bot. 2003, 90, 339-346. [CrossRef] [PubMed]

44. Cho, K.-S.; Yun, B.-K.; Yoon, Y.-H.; Hong, S.-Y.; Mekapogu, M.; Kim, K.-H.; Yang, T.-J. Complete chloroplast genome sequence of tartary buckwheat (Fagopyrum tataricum) and comparative analysis with common buckwheat (F. esculentum). PLoS ONE 2015, 10, e0125332. [CrossRef] [PubMed]

45. Machado, L.D.O.; Vieira, L.D.N.; Stefenon, V.M.; Oliveira Pedrosa, F.D.; Souza, E.M.D.; Guerra, M.P.; Nodari, R.O. Phylogenomic relationship of feijoa (Acca sellowiana (O.Berg) Burret) with other Myrtaceae based on complete chloroplast genome sequences. Genetica 2017, 145, 163-174. [CrossRef] [PubMed]

46. Cuenoud, P.; Savolainen, V.; Chatrou, L.W.; Powell, M.; Grayer, R.J.; Chase, M.W. Molecular phylogenetics of Caryophyllales based on nuclear $18 \mathrm{~S}$ rDNA and plastid $r b c L$, atpB, and matK DNA sequences. Am. J. Bot. 2002, 89, 132-144. [CrossRef] [PubMed]

47. Techen, N.; Parveen, I.; Pan, Z.; Khan, I.A. DNA barcoding of medicinal plant material for identification. Curr. Opin. Biotech. 2014, 25, 103-110. [CrossRef] [PubMed]

48. Kim, I.; Young Park, J.; Sun Lee, Y.; Lee, H.; Park, H.-S.; Jayakodi, M.; Waminal, N.; Hwa Kang, J.; Joo Lee, T.; Sung, S.; et al. Discrimination and authentication of Eclipta prostrata and E. alba based on the complete chloroplast genomes. Plant Breed. Biotech. 2017, 5, 334-343. [CrossRef]

49. Dong, W.; Xu, C.; Li, C.; Sun, J.; Zuo, Y.; Shi, S.; Cheng, T.; Guo, J.; Zhou, S. ycf1, the most promising plastid DNA barcode of land plants. Sci. Rep. 2015, 5, 8348. [CrossRef] [PubMed]

50. Liu, L.; Wu, D.; Zhang, X. Pharmacognostical studies on root of Gentiana officinalis. J. Chin. Med. Mater. 2008, 31, 1635-1638.

51. Xiong, B.; Zhao, Z.; Ni, L.; Gaawe, D.; Mi, M. DNA-based identification of Gentiana robusta and related species. Chin. Med. Mater. 2015, 40, 4680-4685.

52. Zhang, X.; Ge, X.; Liu, J.; Yuan, Y. Morphological, karyological and molecular delimitation of two gentians: Gentiana crassicaulis versus G. tibetica (Gentianaceae). Acta Phytotaxon. Sin. 2006, 44, 627-640. [CrossRef]

53. Maria, B.; Bengt, O.; Birgitta, B. Phylogenetic relationships within the Gentianales based on $n d h F$ and $r b c L$ sequences, with particular reference to the Loganiaceae. Am. J. Bot. 2000, 87, 1029-1043.

54. Yang, L.L.; Li, H.L.; Wei, L.; Yang, T.; Kuang, D.Y.; Li, M.H.; Liao, Y.Y.; Chen, Z.D.; Wu, H.; Zhang, S.Z. A supermatrix approach provides a comprehensive genus-level phylogeny for Gentianales. J. Syst. Evol. 2016, 54, 400-415. [CrossRef]

55. Leebens-Mack, J.; Raubeson, L.A.; Cui, L.; Kuehl, J.V.; Fourcade, M.H.; Chumley, T.W.; Boore, J.L.; Jansen, R.K.; Depamphilis, C.W. Identifying the basal angiosperm node in chloroplast genome phylogenies: Sampling one's way out of the Felsenstein zone. Mol. Biol. Evol. 2005, 22, 1948-1963. [CrossRef] [PubMed] 
56. Doyle, J.J. A rapid DNA isolation procedure for small quantities of fresh leaf tissue. Phytochem. Bull. 1987, 19, 11-15.

57. Patel, R.K.; Jain, M. NGS QC Toolkit: A toolkit for quality control of next generation sequencing data. PLOS ONE 2012, 7, e30619. [CrossRef] [PubMed]

58. Langmead, B.; Salzberg, S.L. Fast gapped-read alignment with Bowtie 2. Nat. Methods 2012, 9, 357-359. [CrossRef] [PubMed]

59. Bankevich, A.; Nurk, S.; Antipov, D.; Gurevich, A.A.; Dvorkin, M.; Kulikov, A.S.; Lesin, V.M.; Nikolenko, S.I.; Pham, S.; Prjibelski, A.D. SPAdes: A new genome assembly algorithm and its applications to single-cell sequencing. J. Comput. Biol. 2012, 19, 455-477. [CrossRef] [PubMed]

60. Hahn, C.; Bachmann, L.; Chevreux, B. Reconstructing mitochondrial genomes directly from genomic next-generation sequencing reads-A baiting and iterative mapping approach. Nucleic Acids Res. 2013, 41, e129. [CrossRef] [PubMed]

61. Wyman, S.K.; Jansen, R.K.; Boore, J.L. Automatic annotation of organellar genomes with DOGMA. Bioinformatics 2004, 20, 3252-3255. [CrossRef] [PubMed]

62. Lohse, M.; Drechsel, O.; Kahlau, S.; Bock, R. OrganellarGenomeDRAW-A suite of tools for generating physical maps of plastid and mitochondrial genomes and visualizing expression data sets. Nucleic Acids Res. 2013, 41, W575-W581. [CrossRef] [PubMed]

63. Kurtz, S.; Choudhuri, J.V.; Ohlebusch, E.; Schleiermacher, C.; Stoye, J.; Giegerich, R. REPuter: The manifold applications of repeat analysis on a genomic scale. Nucleic Acids Res. 2001, 29, 4633-4642. [CrossRef] [PubMed]

64. Benson, G. Tandem repeats finder: A program to analyze DNA sequences. Nucleic Acids Res. 1999, $27,573$. [CrossRef] [PubMed]

65. Thiel, T.; Michalek, W.; Varshney, R.; Graner, A. Exploiting EST databases for the development and characterization of gene-derived SSR-markers in barley (Hordeum vulgare L.). Theor. Appl. Genet. 2003, 106, 411-422. [CrossRef] [PubMed]

66. Yang, Z. PAML 4: Phylogenetic analysis by maximum likelihood. Mol. Biol. Evol. 2007, 24, $1586-1591$. [CrossRef] [PubMed]

67. Frazer, K.A.; Pachter, L.; Poliakov, A.; Rubin, E.M.; Dubchak, I. VISTA: Computational tools for comparative genomics. Nucleic Acids Res. 2004, 32 (Suppl. 2), W273-W279. [CrossRef] [PubMed]

68. Zhang, Y.-J.; Ma, P.-F.; Li, D.-Z. High-throughput sequencing of six bamboo chloroplast genomes: Phylogenetic implications for temperate woody bamboos (Poaceae: Bambusoideae). PLoS ONE 2011, 6, e20596. [CrossRef] [PubMed]

69. Koressaar, T.; Remm, M. Enhancements and modifications of primer design program Primer3. Bioinformatics 2007, 23, 1289-1291. [CrossRef] [PubMed]

70. Bi, G.; Mao, Y.; Xing, Q.; Cao, M. HomBlocks: A multiple-alignment construction pipeline for organelle phylogenomics based on locally collinear block searching. Genomics 2018, 110, 18-22. [CrossRef] [PubMed]

71. Katoh, K.; Standley, D.M. MAFFT multiple sequence alignment software version 7: Improvements in performance and usability. Mol. Biol. Evol. 2013, 30, 772-780. [CrossRef] [PubMed]

72. Posada, D.; Crandall, K.A. Modeltest: Testing the model of DNA substitution. Bioinformatics 1998, 14, 817-818. [CrossRef] [PubMed]

73. Swofford, D.L. Commands Used in the PAUP Block in PAUP 4.0: Phylogenetic Analysis Using Parsimony 132-135; Smithsonian Institution: Washington, DC, USA, 1998.

74. Stamatakis, A. RAxML version 8: A tool for phylogenetic analysis and post-analysis of large phylogenies. Bioinformatics 2014, 30, 1312-1313. [CrossRef] [PubMed]

75. Ronquist, F.; Teslenko, M.; van der Mark, P.; Ayres, D.L.; Darling, A.; Höhna, S.; Larget, B.; Liu, L.; Suchard, M.A.; Huelsenbeck, J.P. MrBayes 3.2: Efficient Bayesian phylogenetic inference and model choice across a large model space. Syst. Biol. 2012, 61, 539-542. [CrossRef] [PubMed]

(C) 2018 by the authors. Licensee MDPI, Basel, Switzerland. This article is an open access article distributed under the terms and conditions of the Creative Commons Attribution (CC BY) license (http:/ / creativecommons.org/licenses/by/4.0/). 